\title{
PENGARUH MOTIVATION DAN WORK DISCIPLINE TERHADAP EMPLOYEE PERFORMANCE (STUDI KASUS PADA KARYAWAN PT. MNC SKY VISION SUKABUMI)
}

\author{
Ryan Kurniawan \\ Program Studi Manajemen, Universitas Widyatama \\ ryan.kurniawan@widyatama.ac.id \\ Diky Aulia Akmal \\ Program Studi Manajemen, Institut Manajemen Wiyata Indonesia \\ dikyaulia95@gmail.com
}

\begin{abstract}
The purpose of this study was to determine the effect of dimensions or variables, motivation and work discipline on employee performance. Methodology: The research method uses a survey method using a questionnaire distributed to 51 MNC Sky Vision employees. While the instrument quality testing techniques include validity, reliability and normality tests. And data analysis techniques using quantitative analysis, while for hypothesis testing using multiple linear regression analysis. Results: based on the results of the t test (partial) conducted that the motivation variable does not affect the performance of employees with a significance value above $0.05(0.074 \leq 0.05)$, while for work discipline variables affect the performance of employees with a significance value below $0,05(0.00 \leq 0.05)$. Based on the $F$ test (simultaneous) motivation and work discipline simultaneously have a positive effect on employee performance with a significance value below $0.05(0.000 \leq 0.05)$. But, in relation to the independent variable on the dependent variable, motivation and work discipline only have an effect of $42.3 \%$ on employee performance and $57.7 \%$ are influenced by variables not examined in this study. Limitations of the study: An analysis of the influence of motivation and work discipline is only done in one branch and only two dimensions or variables are tested. It is expected that the application of motivation can be formulated and adjusted to the existing working conditions in the company.
\end{abstract}

Keywords: motivation, work discipline, and employee performance

\section{Pendahuluan}

Perkembangan ilmu pengetahuan dan ilmu teknologi yang pesat saat ini sangat berpengaruh terhadap kemajuan bisnis, Persaingan yang ketat menyebabkan perusahaan dituntut untuk mampu meningkatkan daya saing dalam menjaga kelangsungan hidup perusahaan. Salah satu antisipasi yang yang dilakukan oleh perusahaan adalah dengan pengembangan sumber daya manusia yang lebih terampil dan berkualitas.
Sumber daya manusia pada hakikatnya merupakan asset utama dan bagian penting dari suatu organisasi maupun perusahaan. Sumber daya manusia yang berkualitas merupakan hal yang penting bagi kelangsungan hidup organisasi, maju atau tidaknya suatu organisasi sangat bergantung pada sumber daya manusianya (Katiandagho, Mandey, \& Mananeke, 2014).

Keunggulan kompetitif akan tercapai apabila pihak manajemen dapat mengelola jantung aktivitas perusahaan dengan 
mendorong sumber daya manusianya atau yang lebih dikenal dengan istilah karyawan secara benar dan tepat. Meskipun suatu organisasi memiliki sumber daya lain yang baik, peralatan kerja yang canggih, metode yang bagus maupun anggaran dana yang banyak, tetapi apabila sumber daya manusia yang dimiliki tidak berkualitas dan tidak mendapatkan pengelolaan yang serius, maka organisasi akan mengalami kesulitan dalam mencapai tujuan. Dengan kata lain kinerja karyawan tidak sesuai harapan perusahaan (Mangkunegara, 2016).

Kinerja merupakan hasil pekerjaan yang dicapai seseorang berdasarkan tanggung jawab yang diberikan kepadanya. Kinerja yang baik merupakan hal yang penting bagi perusahaan maupun karyawan itu sendiri. (Hasibuan \& Hasibuan, 2016) menyatakan bahwa kinerja adalah hasil kerja yang diraih oleh seseorang dalam melaksanakan tugas kerja yang diberikan kepadanya (Sagala \& Rivai, 2013).

Pencapaian kinerja yang baik harus didukung dengan karyawan yang memiliki motivasi dan disiplin kerja yang tinggi untuk meningkatkan kemampuan dari karyawan tersebut. Sehingga para karyawan akan dapat bekerja sesuai dengan keahlian maupun kemampuan yang mereka miliki dan menghasilkan kinerja yang memuaskan bagi perusahaan (Rozalia, 2015).

Menurut (Hasibuan \& Hasibuan, 2016) Motivasi kerja merupakan hal yang penting dalam meningkatkan suatu efektifitas kerja, karena orang yang memiliki motivasi kerja yang tinggi akan berusaha dengan sekuat tenaga agar pekerjaannya dapat berhasil dengan sebaik-baiknya.
Disiplin kerja juga merupakan suatu hal yang penting di dalam perusahaan, Upaya dalam memberikan kedisiplinan tersebut pada dasarnya merupakan suatu upaya dalam meningkat kinerja karyawan pada perusahaan. Menurut (Sagala \& Rivai, 2013) disiplin kerja adalah suatu alat yang digunakan para manajer untuk berkomunikasi dengan karyawan agar mereka bersedia untuk mengubah suatu perilaku dan untuk meningkatkan kesadaran juga kesediaan seseorang agar menaati semua peraturan dan norma sosial yang berlaku di suatu perusahaan (Sagala \& Rivai, 2013).

PT MNC Sky Vision Tbk adalah perusahaan pemegang lisensi pendistribusian tayangan televisi berlangganan melalui satelit pertama di Indonesia yang berada di bawah naungan MNC Media yang merupakan grup media terintegrasi terbesar di Indonesia. Dari hasil analisa data yang dilakukan, hasil penjualan pada PT MNC Sky Vision mengalami penurunan yang signifikan dibandingkan dengan tahun 2018.

Berikut disajikan data penjualan tahun 2018 - 2019 dari PT MNC Sky Vision TBK Sukabumi:

Tabel 1

Data Penjualan Tahun 2018 - 2019

\begin{tabular}{cccc}
\hline No & Bulan & $\begin{array}{c}\text { Pencapaian } \\
\text { tahun 2018 }\end{array}$ & $\begin{array}{c}\text { Pencapaian } \\
\text { tahun 2019 }\end{array}$ \\
\hline 1 & Jan & 328 & 315 \\
\hline 2 & Feb & 369 & 331 \\
\hline 3 & Maret & 411 & 279 \\
\hline 4 & April & 429 & 237 \\
\hline 5 & Mei & 428 & 284 \\
\hline 6 & Juni & 275 & 230 \\
\hline & Total & $\mathbf{2 . 2 4 0}$ & $\mathbf{1 . 6 7 6}$ \\
\hline
\end{tabular}

Sumber: MNC sky vision Sukabumi 
Dari data Diatas, dapat dilihat bahwa pada tahun 2018 tingkat angka penjualan dari setiap bulannya mengalami peningkatan. Jika dibandingkan dengan tahun 2019 dari bulan J Januari - Juni terlihat bahwa hasil penjualan mengalami penurunan yang cukup signifikan (MNC Sky Vision Sukabumi, 2020).

Pada awal bulan Januari angka penjualan hanya mencapai 315 dan bulan februari mengalami kenaikan angka penjulan dengan jumlah 331, pada bulan maret dan april angka penjualan kembali menurun hanya mencapai 279 , dan april 237, bulan mei penjualan meningkat mencapai 284 dan pada bulan juni angka penjualan menurun secara drastis yaitu hanya mencapai 230. Jika dibandingkan Total penjualan tahun 2018 mencapai angka penjualan 2.240 sedangkan pada tahun 2019 hanya mencapai total penjualan 1.676 (MNC Sky Vision Sukabumi, 2020).

Dari hasil data di atas, untuk dapat mengetahui faktor yang mempengaruhi penurunan pada tingkat penjualan PT MNC Sky Vision tersebut maka penulis ingin menganalisa apakah ada pengaruh dari motivasi dan disiplin kerja terhadap kinerja karyawan PT MNC Sky Vision dengan melakukan penelitian dengan judul "Pengaruh Motivasi dan Disiplin kerja terhadap Kinerja karyawan MNC Sky Vision Sukabumi”.

Tujuan yang dilakukan bertujuang untuk 1) mengetahui apakah motivasi berpengaruh secara positif dan signifikan terhadap kinerja karyawan. 2) mengetahui apakah disiplin kerja berpengaruh secara positif dan signifikan terhadap kinerja karyawan dan 3) mengetahui apakah motivasi dan disiplin kerja berpengaruh secara simultan terhadap kinerja karyawan.

\section{Tinjauan Pustaka}

\section{Motivasi (Motivation)}

Baharuddin

Latief

mengemukakan dengan terbentuknya motivasi yang kuat, maka akan dapat membuahkan hasil atau kinerja yang baik sekaligus berkualitas dari pekerjaan yang dilaksanakannya (Tindow, Mekel, \& Sendow, 2014). Hal ini berarti bahwa setiap peningkatan motivasi yang dimiliki oleh karyawan dalam melaksanakan pekerjaannya akan memberikan peningkatan terhadap kinerjanya.

Sedangkan menurut pendapat lain Motivasi adalah merupakan sesuatu yang mendorong orang untuk berbuat sesuatu (Hasibuan \& Hasibuan, 2016).

Berdasarkan pengertian diatas disimpulkan bahwa motivasi merupakan kegiatan yang mengakibatkan, menyalurkan, memelihara dan mendorong perilaku manusia.

\section{Disiplin Kerja (Work Discipline)}

Disiplin adalah suatu bentuk pelatihan yang berusaha memperbaiki dan membentuk pengetahuan, sikap dan perilaku pegawai sehingga para pegawai tersebut secara sukarela berusaha bekerja kooperatif dengan para pegawai yang lain serta meningkatkan prestasi kerja (Siagian, 2013.

Definisi lain disiplin kerja diartikan sebagai pelaksanaan manajemen untuk memperteguh pedoman-pedoman organisasi. Kadang-kadang, perilaku pekerja dalam organisasi menjadi sangat mengganggu sehingga berdampak dengan kinerja yang menurun (Mangkunegara, 2016).

Dari beberapa pendapat ahli di atas dapat disimpulkan bahwa disiplin kerja sangat diperlukan dalam 
organisasi, karena disiplin merupakan suatu bentuk upaya memperbaiki diri dan membentuk sikap karyawan yang terlambat, mengabaikan prosedur keselamatan, tidak mengikuti petunjuk yang telah ditentukam atau terlibat masalah dengan rekan kerjanya.

\section{Kinerja Karyawan (Employee Performance)}

Kinerja secara umum merupakan gambaran prestasi yang dicapai oleh organisasi/perusahaan dalam operasionalnya (Mardalena, 2017). Sebuah organisasi memerlukan manusia sebagai sumber daya pendukung utama untuk mencapai tujuan yang telah ditetapkan.

Sedangkan dalam pengertian lain, kinerja karyawan adalah hasil kerja secara kualitas yang dicapai oleh seseorang karyawan dalam melaksanakan tugasnya sesuai dengan tanggung jawab yang diberikan (Mangkunegara, 2016).

Dari beberapa definisi di atas, disimpulkan bahwa kinerja merupakan hasil dari seseorang secara keseluruhan selama periode tertentu dalam melaksanakan tugas, yang secara langsung mempengaruhi keberhasilan sebuah perusahaan.

Mengacu pada kerangka teoritas yang telah dijabarkan diatas, dapat dikemukakan model analisis seperti yang tercantum pada gambar dibawah ini:

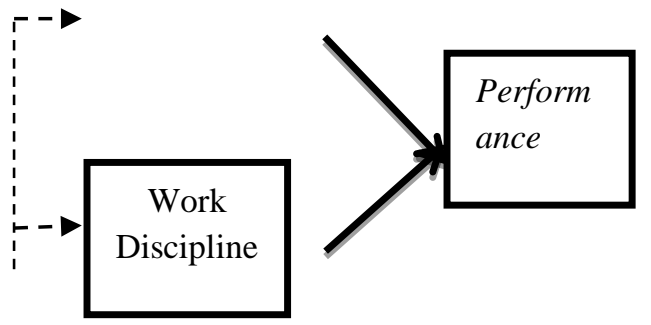

\section{Hipotesis}

Berdasarkan landasan teori dan kerangka pemikiran di atas, maka hipotesis penelitian dirumuskan sebagai berikut:

$$
\begin{aligned}
& \text { Hipotesis } \text { Nol }\left(\boldsymbol{H}_{0}\right) \\
& \mathrm{H}_{0-1}= \text { Tidak ada pengaruh positif } \\
& \text { dan signifikan antara } \\
& \text { motivation terhadap } \\
& \text { employee performance } \\
& \mathrm{H}_{0-2}= \text { Tidak ada pengaruh positif } \\
& \text { dan signifikan antara work } \\
& \text { discipline terhadap employee } \\
& \text { performance } \\
&= \text { Tidak ada pengaruh positif } \\
& \text { dan signifikan antara } \\
& \text { motivation dan work } \\
& \text { discipline terhadap employee } \\
& \text { performance }
\end{aligned}
$$

\section{Hipotesis Alternatif $\left(\mathrm{H}_{a}\right)$}

$$
\begin{aligned}
& \mathrm{H}_{\mathrm{a}-1}=\text { Ada pengaruh positif dan } \\
& \text { signifikan antara } \\
& \text { motivation terhadap } \\
& \text { employee performance } \\
& \mathrm{H}_{\mathrm{a}-2}=\text { Ada pengaruh positif dan } \\
& \text { signifikan antara work } \\
& \text { discipline terhadap } \\
& \text { employee performance } \\
& \mathrm{H}_{\mathrm{a}-3}=\text { Ada pengaruh positif dan } \\
& \text { signifikan antara } \\
& \text { motivation dan work } \\
& \text { discipline terhadap } \\
& \text { employee performance }
\end{aligned}
$$

\section{Metode Penelitian}

Metode yang digunakan dalam penelitian ini Metode yang digunakan dalam penelitian ini adalah menggunakan metode kuantitatif, dengan mengambil tiga objek analisis atau 3 variabel yaitu: motivation (X1), work discipline (X2) dan employee performance (Y). Penelitian ini dilakukan di PT. MNC Sky Vision Sukabumi yang berlokasi di Jl. Brawijaya 
no3 kota sukabumi. dengan populasi sebanyak 51 orang.

Sampel dalam penelitian ini menggunakan seluruh populasi, yaitu sebanyak 51 orang. Teknik penelitian yang digunakan adalah dengan menggunaka angket (questioner) dengan sumber data perimer dan sekunder, yaitu data yang bersumber dari PT. MNC Sky Vision Sukabumi dan dari hasil kepustakaan yang didapatkan oleh peneliti.

Item pernyataan dalam variabel motivation menggunakan 6 pernyataan, sedangkan pada variabel work discipline menggunakan 6 pernyataan, sementara pada variabel employee performance jumlah pernyataan yang diberikan ada 8 pernyataan. Pengujian kualitas instrumen atau pernyataan - pernyataan yang ada ini menggunakan uji validitas, uji reliabilitas dan uji asumsi klasik, dan untuk uji hipotesis menggunakan uji analisis regresi linear berganda, analisis koefisien determinasi (R2), uji T (Parsial) dan uji $\mathrm{F}$ (Simultan), Dalam pelaksanaannya penelitian ini menggunakan alat bantuan bantuan software Microsoft Excel 2013 dan IBM SPSS v.25 (Statistical Product and Service Solution).

\section{Hasil Penelitian dan Pembahasan}

\section{A. Hasil Penelitian}

\section{Karakteristik responden}

Berdasarkan hasil analisa mengenai klasifikasi responden, berikut klasifikasi yang paling mendominasi pada karyawan di Rumah Sakit Ridogalih

Tabel 2

Klasifikasi Responden

\begin{tabular}{llcc}
\hline $\begin{array}{c}\text { Faktor } \\
\text { Demografi }\end{array}$ & \multicolumn{1}{c}{ Klasifikasi } & Jml Responden & \% \\
\hline Jenis kelamin & Laki - Laki & 48 & $94 \%$ \\
\hline Usia & $>32$ tahun & 20 & $39 \%$ \\
\hline Lama Bekerja & $1-5$ tahun & 39 & $41 \%$ \\
\hline Pendidikan & SMA & 37 & $72 \%$ \\
\hline
\end{tabular}

2. Pengujian kualitas instrumen

\section{a. Hasil uji validitas}

Uji validitas digunakan untuk mengukur sah atau valid tidaknya suatu kuesioner. Suatu kuesioner dikatakan valid jika pertanyaan atau pernyataan pada kuesioner mampu untuk mengungkapkan sesuatu yang akan diukur oleh kuesioner tersebut (Ghozali, 2016).

b. Motivasi (Motivation) 
Tabel 3

Hasil Uji Validitas Indikator Variabel Motivation

\begin{tabular}{cccc}
\hline Indikator & $\begin{array}{c}\mathbf{r} \\
\text { hitung }\end{array}$ & $\begin{array}{c}\mathbf{r} \\
\text { table }\end{array}$ & Keterangan \\
\hline KFB1 & 0.666 & 0.266 & VALID \\
\hline KFB2 & 0.463 & 0.266 & VALID \\
\hline KAP1 & 0.712 & 0.266 & VALID \\
\hline KAP2 & 0.608 & 0.266 & VALID \\
\hline KAD1 & 0.639 & 0.266 & VALID \\
\hline KAD2 & 0.726 & 0.266 & VALID \\
\hline
\end{tabular}

Sumber: Hasil olah data 2019

c. Work Dicipline (Disiplin Kerja)

Tabel 4

Hasil Uji Validitas Indikator Variabel Work Dicipline

\begin{tabular}{cccc} 
Indikator & $\begin{array}{c}\mathbf{r} \\
\text { hitung }\end{array}$ & $\begin{array}{r}\mathbf{r} \\
\text { table }\end{array}$ & Keterangan \\
\hline TAW1 & 0.580 & 0.226 & VALID \\
\hline TAW2 & 0.497 & 0.226 & VALID \\
\hline TTP1 & 0.664 & 0.226 & VALID \\
\hline TTP2 & 0.617 & 0.226 & VALID \\
\hline TAP1 & 0.652 & 0.226 & VALID \\
\hline TAP2 & 0.640 & 0.226 & VALID \\
\hline \multicolumn{4}{c}{ Sumber: Hasil olah data 2019 }
\end{tabular}

Dari hasil uji validitas diatas dapat disimpulkan bahwa semua item pernyataan pada

3. Employee performance (Kinerja Karyawan) variabel Work Dicipline adalah valid.

Tabel 5

Hasil uji validitas indikator variabel Employee performance

\begin{tabular}{cccc} 
Indikator & $\begin{array}{c}\mathbf{r} \\
\text { hitung }\end{array}$ & $\begin{array}{c}\mathbf{r} \\
\text { table }\end{array}$ & Keterangan \\
\hline KDH1 & 0.741 & 0.266 & VALID \\
\hline KDH2 & 0.685 & 0.266 & VALID \\
\hline KUH1 & 0.518 & 0.266 & VALID \\
\hline KUH2 & 0.562 & 0.266 & VALID \\
\hline EF1 & 0.712 & 0.266 & VALID \\
\hline EF2 & 0.729 & 0.266 & VALID \\
\hline KD1 & 0.783 & 0.266 & VALID \\
\hline KD2 & 0.459 & 0.266 & VALID \\
\hline
\end{tabular}

Sumber: Hasil olah data 2019

Dari hasil uji validitas diatas dapat disimpulkan bahwa semua item pernyataan pada variabel Employee performance adalah valid. 


\section{Uji Realibilitas}

Uji realibilitas sebagai alat untuk mengukur suatu kuesioner dapat dikatakan reliabel atau handal jika jawaban seseorang terhadap pernyataan adalah konsisten atau stabil dari waktu ke waktu (Ghozali, 2016).

\section{Tabel 6}

Hasil uji realibilitas

\begin{tabular}{cccc}
\hline Variabel & $\begin{array}{c}\text { Cronbach } \\
\text { Alpha }\end{array}$ & $\begin{array}{c}\text { Cronbach } \\
\text { Alpha yang } \\
\text { di syaratkan }\end{array}$ & Keterangan \\
\hline Motivation $\left(X_{1}\right)$ & 0.708 & $>0.6$ & Reliabel \\
\hline $\begin{array}{c}\text { Work } \\
\text { Discipline }\left(X_{2}\right)\end{array}$ & 0.653 & $>0.6$ & Reliabel \\
\hline Employee Perpormance $(Y)$ & 0.802 & $>0.6$ & Reliabel \\
\hline
\end{tabular}

Sumber: Hasil olah data 2019

Dari hasil uji realibilitas diatas dapat disimpulkan bahwa ketiga variabel dalam penelitian ini adalah reliable atau andal. dihasilkan berdistribusi normal atau berdistribusi tidak normal (Imam, 2011).

\section{Asumsi Klasik}

\section{a) Uji normalitas}

Uji normalitas dilakukan untuk mengetahui apakah data pada persamaan regresi yang

Tabel 7

Hasil Uji Normalitas

\begin{tabular}{|c|c|c|}
\hline \multicolumn{3}{|c|}{$\begin{array}{c}\text { One-Sample Kolmogorov-Smirnov } \\
\text { Test }\end{array}$} \\
\hline & & $\begin{array}{l}\text { Unstandardi } \\
\text { zed Residual }\end{array}$ \\
\hline $\mathrm{N}$ & & 51 \\
\hline \multirow{2}{*}{$\begin{array}{l}\text { Normal } \\
\text { Parameters }\end{array}$} & Mean & .0000000 \\
\hline & $\begin{array}{l}\text { Std. } \\
\text { Deviation }\end{array}$ & 2.72210205 \\
\hline \multirow{3}{*}{$\begin{array}{l}\text { Most Extreme } \\
\text { Differences }\end{array}$} & Absolute & .115 \\
\hline & Positive & .115 \\
\hline & Negative & -.059 \\
\hline \multicolumn{2}{|l|}{ Test Statistic } & .115 \\
\hline \multicolumn{2}{|c|}{ Asymp. Sig. (2-tailed) } & $.091^{\mathrm{c}}$ \\
\hline
\end{tabular}

Hasil data tabel di atas menunjukkan bahwa pada kolom kolmogrov-smirnov dapat diketahui nilai signifikansi (Asyump.sig 2 tailed) yaitu sebesar $0,091(0,091>0,05)$ 
maka nilai residualnya adalah normal.

\section{b) Uji Multikolinearitas}

Imam Ghozali menyatakan Indikator model regresi yang baik adalah tidak adanya korelasi di antara variabel independen, untuk mendeteksi ada atau tidaknya multikolinearitas di dalam model regresi.

Dari hasil uji multikolinearitas menggunakan SPSS, dapat diketahui bahwa variabel X1 (Motivation) dan variabel X2 (Work Discipline) mempunyai nilai output VIF yang sama yaitu sebesar 1,096 dan nilai output tolerance masing-masing variabel menunjukkan angka yang sama pula yaitu 0,913 . Setiap variabel bebas mempunyai nilai VIF $<10$ dan nilai tolerance $>0,1$. Jadi dapat disimpulkan bahwa tidak terjadi multikolinearitas antar variabel bebas dalam model regresi ini.

\section{c) Uji Heteroskedastisitas}

Uji heteroskedastisitas menurut Imam Ghozali bertujuan untuk mengetahui apakah di dalam model regresi terjadi ketidaksamaan variance dari suatu residual pengamatan ke pengamatan lain.

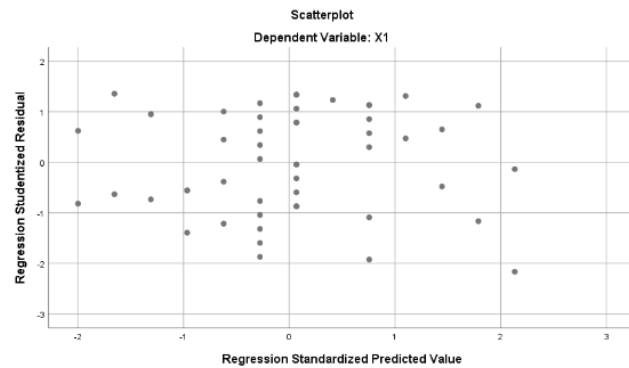

Gambar 2

Hasil Uji Heteroskedastisitas

Sumber: Hasil Olah Data 2019

Dari hasil uji heteroskedastisitas diatas, yaitu melalui grafik scater plot dapat disimpulkan bahwa pada model regresi pengaruh variabel $\mathrm{X} 1$ dan $\mathrm{X} 2$ secara bersama-sama terhadap variabel $Y$ tidak terjadi Heteroskedastisitas karena titik-titik menyebar secara acak dan tidak membentuk pola tertentu.

\section{Analisis Deskriptif}

a) Motivation

Dari hasil analisa responden melalui pengisian kuesioner, maka dapat diperoleh data sub variabel yang paling mempengaruhi Motivation adalah sebagai berikut:

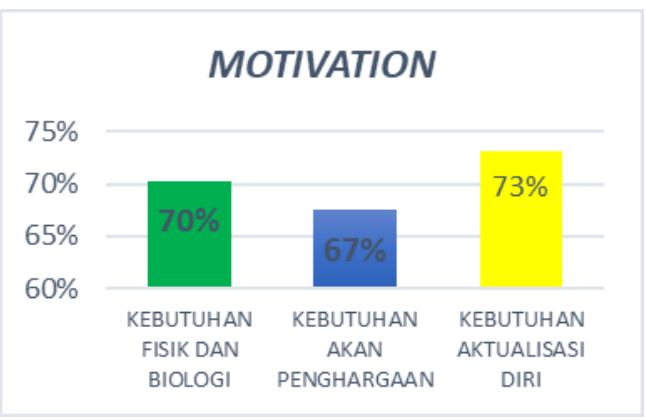

Grafik 1

Sub variabel work stress yang paling mempengaruhi

Sumber: Hasil Olah Data 2019 
b) Employee Performance

Dari hasil analisa responden melalui pengisian kuesioner, maka dapat diperoleh data sub variabel yang paling mempengaruhi employee performance adalah sebagai berikut:

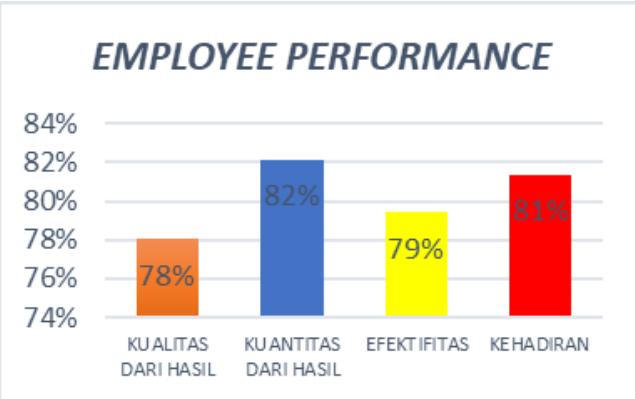

\section{Grafik 2}

Sub variabel turnover intention yang paling mempengaruhi

Sumber: Hasil Olah Data 2019

\section{Pengujian hipotesis}

a) Uji regresi linear berganda

Hasil analisis dengan menggunakan program SPSS versi 25 for Windows di atas diperoleh hasil persamaan regresi berganda sebagai berikut:
$\mathrm{Y}=10,620+0,198 \mathrm{X} 1+$ $0,727 \mathrm{X} 2$ Persamaan regresi tersebut mempunyai makna sebagai berikut:

1) Konstanta $=10,620$

Jika variabel motivation dan work discipline sama dengan nol, maka variabel employee performance sebesar 10,620

2) Koefisien $X 1=0,198$

Jika variabel motivation mengalami kenaikan sebesar satu satuan, sementara work discipline dianggap tetap, maka akan menyebabkan peningkatan employee performance sebesar 0,198

3) Koefisien $X 2=0,727$

Jika variabel work discipline mengalami kenaikan sebesar satu satuan, sementara motivation dianggap tetap, maka akan menyebabkan peningkatan employee performance sebesar 0.727 .

b) Uji Koefisien Determinasi $\left(R^{2}\right)$

Tabel 8

Hasil Uji Koefisien Determinasi $\left(\mathbf{R}^{2}\right)$

\begin{tabular}{lcrrrr}
\hline \multicolumn{6}{c}{ Model Summary $^{\mathbf{b}}$} \\
\hline \multirow{2}{*}{ Model } & \multirow{2}{*}{$\mathbf{R}$} & $\begin{array}{c}\text { R } \\
\text { Square }\end{array}$ & $\begin{array}{c}\text { Adjusted } \\
\text { R Square }\end{array}$ & $\begin{array}{c}\text { Std. Error of the } \\
\text { Estimate }\end{array}$ & $\begin{array}{c}\text { Durbin- } \\
\text { Watson }\end{array}$ \\
\hline 1 & $.668^{\mathrm{a}}$ & .446 & .423 & 2.778 & 1.329 \\
\hline
\end{tabular}

Sumber: Hasil olah data 2019

Tabel 8 menunjukkan perolehan nilai Adjusted $\mathrm{R}$ Square (R2) sebesar $0,423=$ $42,3 \%$, maka dapat disimpulkan bahwa variabel motivation dan work discipline secara bersama-sama memengaruhi variabel employee performance sebesar 42,3\%, sedangkan sisanya sebesar $57,7 \%$ 
dipengaruhi oleh faktor lain di luar variabel penelitian yang diteliti.

\section{Uji T (Parsial)}

Menurut Ghozali pada dasarnya, uji $\mathrm{T}$ digunakan untuk menunjukkan seberapa jauh pengaruh satu variabel independen secara parsial dalam menerangkan variasi variabel independen (Ghozali, 2016).

Tabel 9

Hasil Uji T (Uji Parsial)

\begin{tabular}{|c|c|c|c|c|c|c|}
\hline \multicolumn{7}{|c|}{ Coefficients ${ }^{\mathrm{a}}$} \\
\hline & & $\begin{array}{r}\text { Unsta } \\
\mathrm{Coe}\end{array}$ & $\begin{array}{l}\text { idardized } \\
\text { ficients }\end{array}$ & $\begin{array}{l}\text { Standardized } \\
\text { Coefficients }\end{array}$ & & \\
\hline \multicolumn{2}{|c|}{ Model } & $\mathrm{B}$ & Std. Error & Beta & $\mathrm{T}$ & Sig. \\
\hline \multirow[t]{3}{*}{1} & (Constant) & 10.620 & 3.490 & & 3.043 & .004 \\
\hline & motivasi & .198 & .109 & .205 & 1.827 & .074 \\
\hline & Disiplin kerja & .727 & .142 & .577 & 5.133 & .000 \\
\hline
\end{tabular}

a. Dependent Variable: kinerjakaryawan

Sumber: Hasil olah data 2019

Dari hasil uji T menggunakan aplikasi SPSS Versi 25, dapat diketahui bahwa Nilai $\mathrm{t}$ hitung variabel motivation lebih kecil dari nilai $\mathrm{t}$ tabel $(1,827 \leq 2,01063)$ dengan tingkat signifikan di atas 0,05 yaitu sebesar $0,074(0,074 \geq$ 0,05) maka Ho diterima dan Ha ditolak. Sedangkan nilai $\mathrm{t}$ hitung variabel work discipline (X2) lebih besar dari pada nilai $t$ tabel $(5,133 \geq$ 2,01063) dengan tingkat signifikan di bawah 0,05 yaitu 0,000, maka Ha diterima dan Ho ditolak. Cara pengambilan keputusan uji parsial dalam analisis regresi dapat disimpulkan sebagai berikut:

1) Variabel motivation (X1) secara parsial tidak berpengaruh positif dan signifikan terhadap employee performance (Y)

2) Variabel work discipline (X2) secara parsial berpengaruh positif dan signifikan terhadap employee performance $(\mathrm{Y})$.

\section{Uji F (Simultan)}

Tabel 10

Hasil Uji T (Uji Parsial)

ANOVA $^{\mathrm{a}}$

\begin{tabular}{|c|c|c|c|c|c|}
\hline Model & $\begin{array}{l}\text { Sum of } \\
\text { Squares }\end{array}$ & Df & $\begin{array}{l}\text { Mean } \\
\text { Square }\end{array}$ & $\mathrm{F}$ & Sig. \\
\hline 1 Regression & 298.018 & 2 & 149.009 & 19.305 & $.000^{\mathrm{b}}$ \\
\hline Residual & 370.492 & 48 & 7.719 & & \\
\hline Total & 668.510 & 50 & & & \\
\hline
\end{tabular}

Sumber: Hasil olah data 2019 
Hasil output SPSS pada tabel Anova di atas menunjukkan bahwa variabel motivation dan work discipline memiliki nilai $\mathrm{F}$ hitung yaitu sebesar 19,305 dengan nilai signifikan 0,000. Nilai f-tabel dapat dicari dengan menggunakan tingkat kepercayaan $5 \%$ atau 0,05 . Kriteria penerimaan hipotesis yaitu Ho ditolak apabila nilai signifikansi kurang dari taraf kesalahan 5\% $(0,05)$ dan nilai $F$ hitung $\geq F$ tabel. Nilai signifikan pada variabel motivation dan work discipline kurang dari 5\% atau 0,05 yaitu sebesar $0,000(0,000 \leq 0,05)$ dan nilai $\mathrm{F}$ hitung lebih besar dari $\mathrm{F}$ tabel $(19,305 \geq 3,19)$ sehingga dapat disimpulkan bahwa $\mathrm{H}_{\mathrm{o}}$ ditolak dan $\mathrm{H}_{\mathrm{a}}$ diterima atau motivation dan work discipline secara simultan berpengaruh positif dan signifikan terhadap employee performance.

\section{B. PEMBAHASAN}

\section{Pengaruh Motivation terhadap Employee Performance}

Hasil penelitian yang telah dilakukan oleh peneliti dalam menguji apakah ada pengaruh motivasi (motivation) terhadap kinerja karyawan (employee performance) di PT.MNC Sky Vision Sukabumi menunjukkan bahwa tidak ada pengaruh motivation terhadap employee performance di PT. MNC Sky Vision Sukabumi.

Namun, dari hasil analisis deskriptif yang telah dilakukan, indikator pada variabel motivation yang paling mempengaruhi karyawan terhadap kinerjanya adalah kebutuhan aktualisasi diri karyawan. kebutuhan aktualisasi diri yaitu bagaimana pimpinan selalu memberikan saran dan kritik untuk membangkitkan motivasi karyawan serta memenuhi kebutuhan karyawan untuk mengaktualisasikan dirinya seperti memberikan pelatihan yang dapat meningkatkan kemampuannya. namun pada kenyataannya hal tersebut tidak mempengaruhi karyawan untuk meningkatkan kinerjanya.

2. Pengaruh Work Discipline Terhadap Employee Performance

Hasil penelitian yang dilakukan oleh peneliti dalam menguji apakah ada pengaruh disiplin kerja (work discipline) terhadap employee performance di PT. MNC Sky Vision Sukabumi. Hasil penelitian menunjukkan bahwa adanya pengaruh work discipline terhadap employee performance di PT. MNC Sky Vision Sukabumi. Hal ini dapat dilihat dari hasil tanggapan responden terhadap pernyataan pernyataan yang ada di dalam angket (questioner) dan hasil perhitungan SPSS.

Penelitian yang dilakukan oleh peneliti di MNC Sky Vision Sukabumi menunjukkan hasil bahwa karyawan yang memiliki work discipline yang tinggi akan bekerja dengan baik dan optimal. Work discipline karyawan akan berdampak pada employee 
performance maupun perusahaan sehingga perusahaan dapat menghasilkan output yang tinggi dan mencapai tujuan yang telah ditetapkan. Tingginya work discipline dari hasil analisis akan berdampak pada employee performance, pernyataan tersebut didukung oleh Hasil penelitian uji $\mathrm{t}$ hitung sebesar 5,133 dengan tingkat signifikansi di bawah 0,05 yaitu 0,000. Hasil tersebut menunjukkan bahwa terdapat pengaruh yang positif dan signifikan antara work discipline terhadap employee performance MNC Sky Vision Sukabumi.

3. Pengaruh Motivation Dan Work Discipline Secara Simultan Terhadap Employee Performance

Hasil penelitian yang dilakukan oleh peneliti dalam menguji apakah ada pengaruh antara motivasi (motivation) dan disiplin kerja (work discipline) terhadap kinerja karyawan (employee performance) di PT.MNC Sky Vision Sukabumi. Hasil penelitian menunjukkan bahwa adanya pengaruh motivation dan work discipline secara simultan terhadap employee performance di PT.MNC Sky Vision Sukabumi. Hal ini dapat dilihat dari hasil tanggapan responden terhadap pernyataan-pernyataan yang ada di dalam angket (questioner) dan hasil perhitungan SPSS.

Hasil penelitian yang telah dijelaskan di atas dapat disimpulkan bahwa motivation dan work discipline secara simultan mampu memengaruhi employee performance. Hasil uji $\mathrm{F}$ menunjukkan bahwa kedua variabel independen secara simultan berpengaruh terhadap employee performance. Nilai signifikan pada variabel motivation dan work discipline kurang dari 5\% atau 0,05 yaitu sebesar 0,000 dan nilai $F$ hitung lebih besar dari $\mathrm{F}$ tabel $(19,305>3,19)$ sehingga dapat disimpulkan bahwa motivation dan work discipline secara simultan berpengaruh terhadap employee performance.

\section{Simpulan}

Berdasarkan hasil uji $\mathrm{t}$ (parsial) menunjukkan bahwa tidak adanya pengaruh positif dan signifikan antara motivation terhadap employee performance di PT.MNC Sky Vision Sukabumi. bahwa meskipun manajemen memberikan motivasi kepada para karyawan, hal tersebut tidak memberikan pengaruh terhadap peningkatan kinerja karyawan. Pihak manajemen hanya memberikan kritik kepada karyawan saat kinerjanya kurang baik dan tidak di barengi dengan memberikan saran yang baik atau memberikan solusi atas kendala yang di hadapi oleh karyawan saat di lapangan.

Berdasarkan hasil uji $\mathrm{t}$ (parsial) menunjukkan bahwa adanya pengaruh positif dan signifikan antara work discipline terhadap employee performance di PT. MNC Sky Vision Sukabumi. Hal ini menunjukkan bahwa semakin tinggi tingkat work discipline para karyawan terhadap penyelesaiannya atau melakukan pekerjaan sesuai job description, maka employee performance akan semakin 
meningkat dalam menghasilkan output kinerjanya.

Berdasarkan hasil uji $\mathrm{F}$ (simultan) menunjukkan bahwa adanya pengaruh yang signifikan antara motivation dan work discipline terhadap employee performance di PT. MNC Sky Vision Sukabumi.

\section{Saran}

Bagi peneliti yang akan melakukan penelitian di masa yang akan datang sebaiknya memperluas variabel dan pengukuran variabel penelitia misalnya dengan menggunakan variabel leadership style, jwork satisfaction, dll. sehingga dapat lebih meningkatkan employee performance pada karyawan MNC Sky Vision Sukabumi. Selain itu, diharapkan penelitian selanjutnya menggunakan grand theory motivation yang lainnya selain dari Maslow, misalnya menggunakan teori motivation dari David Mc. Clelland, Herzberg, dll, dalam mengkaji variabel motivation, dan dapat mengkaji lebih dalam tentang work discipline yang pada penelitian ini berpengaruh terhadap employee performance pada karyawan MNC Sky Vision Sukabumi agar diperoleh gambaran yang lebih lengkap lagi sehingga diharapkan hasil penelitian yang akan datang lebih sempurna dari penelitian ini.

Penelitian yang dilakukan oleh peneliti menunjukkan hasil bahwa variabel motivation tidak berpengaruh terhadap employee performance di MNC Sky Vision Sukabumi. Jadi, apabila Manajemen ingin lebih meningkatkan employee performance-nya, maka sebaiknya manajemen MNC Sky Vision Sukabumi bisa lebih fokus untuk meningkatkan Work Discipline karyawan agar employee performance-nya bisa terus meningkat sehingga performance-nya bisa lebih stabil dan bahkan bisa meningkat lagi.

Sedangkan upaya yang perlu dilakukan untuk bisa meningkatkan work discipline karyawan dibutuhkan banyak dukungan dari pihak manajemen MNC Sky Vision Sukabumi. Dukungan yang diberikan oleh manajemen berupa lebih meningkatkan atau memperhatikan lagi kedisiplinan dan tata tertib yang harus di jalankan oleh karyawan guna meningkatan kinerja karyawan lebih baik lagi.

\section{Daftar Pustaka}

Ghozali, I. (2016). APlikasi Analisis Multivariate dengan program IBM SPSS 23. Semarang: Badan Penerbit Universitas DIponogoro.

Hasibuan, Malayu S. P., \& Hasibuan, H. Malayu S. P. (2016). Manajemen sumber daya manusia. Bumi Aksara.

Imam, Ghozali. (2011). Aplikasi analisis multivariate dengan program IBM SPSS 19. Semarang: Badan Penerbit Universitas Diponegoro, 68.

Katiandagho, Christian, Mandey, Silvya L., \& Mananeke, Lisbeth. (2014). Pengaruh Disiplin Kerja Kepemimpinan dan Motivasi terhadap Kinerja Pegawai pada PT. PLN (Persero) Wilayah Suluttenggo Area Manado. Jurnal EMBA: Jurnal Riset Ekonomi, Manajemen, Bisnis Dan Akuntansi, 2(3).

Mangkunegara, A. A. Anwar Prabu. (2016). Manajemen sumber daya manusia perusahaan. PT. Remaja Rosdakarya.

Mardalena, S. d. (2017). Pengantar Manajemen. Yogyakarta: CV Buana. 
Rozalia, Nur Avni. (2015). Pengaruh motivasi kerja dan disiplin kerja terhadap kinerja karyawan (studi kasus pada karyawan PT. Pattindo Malang). Jurnal Administrasi Bisnis, 26(2).

Sagala, Rivai Dan Ella, \& Rivai, Veithzal. (2013). Manajemen Sumber Daya Manusia Untuk Perusahaan. Rajawali Pers, Jakarta.

Tindow, Mohammad Iman, Mekel, Peggy A., \& Sendow, Greis M. (2014). Disiplin kerja, motivasi dan kompensasi pengaruhnya terhadap kinerja karyawan pada pt. bank sulut cabang calaca. Jurnal EMBA: Jurnal Riset Ekonomi, Manajemen, Bisnis Dan Akuntansi, 2(2). 